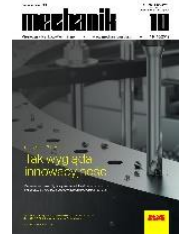

How to cite this article:

Authors: Paweł Karolczak, Dariusz Poroś, Maciej Kowalski

Title of article: „Analysis of selected effects of the conventional and unconventional machining of titanium alloys”

Mechanik, No. 10 (2019)

DOI: https://doi.org/10.17814/mechanik.2019.10.86

\title{
Analysis of selected effects of the conventional and unconventional machining of titanium alloys
}

\author{
PAWEL KAROLCZAK \\ DARIUSZ POROŚ \\ MACIEJ KOWALSKI *
}

Dr inż. Paweł Karolczak, pawel.karolczak@pwr.edu.pl, https://orcid.org/0000-0002-0595-1580- Katedra Obrabiarek i Technologii Mechanicznych, Wydział Mechaniczny, Politechnika Wrocławska, Wrocław, Polska

Dr inż. Dariusz Poroś, dariusz.poros@pwr.edu.pl, https://orcid.org/0000-0002-2336-1859 - Katedra Obrabiarek i Technologii Mechanicznych, Wydział Mechaniczny, Politechnika Wrocławska, Wrocław, Polska

Dr inż. Maciej Kowalski, maciej.kowalski@pwr.edu.pl, https://orcid.org/0000-0003-3413-8334 - Katedra Obrabiarek i Technologii Mechanicznych, Wydział Mechaniczny, Politechnika Wrocławska, Wrocław, Polska

In this article, the results of wire WEDM (wire electrical discharge machining) of Ti6Al4V are collated by turning with modified wiper tool geometry. The electrode is CuZn37 brass wire with a diameter of $0.25 \mathrm{~mm}$ The analysis of 3D geometry of the Ti6Al4V alloy surface after wiper and WEDM cutting is presented. The possibilities and limitations of wiper and WEDM machining of titanium alloys were indicated

KEYWORDS: WEDM, wiper tools, turning, 3D roughness, titanium alloys

\section{Introduction}

Shaping titanium alloys with waste methods is difficult for both technical and economic reasons. It is problematic to obtain satisfactory machining efficiency and low blade wear (and thus low tooling costs) while ensuring adequate surface quality. Therefore, attempts are being made to achieve this goal by means of unconventional machining methods or using special tools in traditional methods of shaping.

\section{Conventional and unconventional titanium machining}

Difficult-to-machine materials, which include titanium alloys, can be shaped by traditional waste methods and unconventional methods. Effective production of elements made of titanium alloys is possible under condition of a proper selection of conventional machining conditions or due to the use of erosive machining or incremental techniques.

In this paper, the authors focused on the capabilities of blades with smoothing geometry and wire electrical discharge machining - WEDM - in relation to machining the titanium alloys.

As it is known, by modifying the radius of the cutting edge rounding, one can - without changing the feedrate value - achieve significantly lower roughness or keep the feedrate significantly higher while maintaining the same roughness [2].

In the work [4], the influence of the conditions of turning with wiper blades on the quality of the machined surface was analyzed. Process of turning the C45 steel under minimal lubrication (MQL) with compressed air and dry cooling was investigated. It has been confirmed that the use of wiper inserts allows for a significant reduction in the roughness parameter compared to machining with ordinary inserts - regardless of the cooling system. Also in machining difficult-to-machine materials, e.g. composites, the use of smoothing blades significantly improves the surface roughness [3]. Therefore, inserts with wiper smoothing geometry can significantly increase the productivity and reduce the machining costs due to the possibility of using high feedrates.

Work on the effects of electro-discharge machining of titanium alloys has been ongoing for years. The results of most experiments indicate that greater efficiency of EDM can be achieved by applying polarization with a positive working electrode - especially when the dielectric is kerosene. This is due to the fact that carbon particles settle on the tool. A carbide layer protects the tool against electrical erosion [6]. Of course, cutting efficiency 
increases as the discharge power increases. Then, higher current density causes more intensive removal of allowance. Increasing the pause time leads to a reduction in performance, however, its shortening must take into account the time necessary to flush the erosion products from the gap. Thermal conductivity and melting point of the workpiece also affect the WEDM performance. Materials with high melting points and higher thermal conductivity are characterized by lower electrical discharge machinability due to the high heat exchange inside the material and with the environment [5].

When WEDM machining of titanium and its alloys, the increase in discharge energy results in increased surface roughness. Low surface roughness is favored by extending the time between discharges. Then the electrode gap is thoroughly cleaned of electro-discharge products. In addition, the effect of dielectric pressure and wire electrode tension on achieving the assumed value of surface roughness is important. Higher flushing pressure makes this task easier. Good flushing of the gap reduces the temperature of the electrode and allows it to stretch more without breaking. Higher electrode tension eliminates wire vibrations [7]. Research on removing thermally changed layer in subsequent passes confirms the possibility of significantly reducing its depth. The effect is visible after three passes [1].

High temperature and fast surface cooling cause uneven temperature distribution between layers of material. Stresses - compressive or tensile - remain in the material after machining. Usually, these are tensile stresses undesirable, because they worsen the mechanical properties of the material. Long pulse time and high discharge current contribute to the formation of high stresses in the surface layer [9]. A variety of wire electrode materials can have significant effect on the stress state. In the case of WEDM machining with a brass electrode, even compressive stresses were obtained on the surface of the material.

An effective way to reduce the negative impact of surface stresses on material properties is stress relaxation through targeted heat treatment [8].

\section{Research methodology}

The aim of the study was to analyze the impact of using the wiper blades on selected technological effects of turning the Ti-6Al-4V alloy. Results of these studies were also to be a source of data for assessing the suitability of WEDM in machining titanium alloys. Chip shape, process efficiency and surface roughness were selected as the parameters for the evaluation of the cutting process. Turning tests were carried out in variable conditions. The chips were collected during the research.

In accordance with the assumed goal, two types of cutting plates were used for testing: traditional CCMT 09 T3 04-MF 1025 and with CCMT 09 T3 04-WF 1025 wiper geometry. The tool material, from which the cutting blades were made, was cemented carbide. Both plates had a layer of titanium nitride coating by PVD. The tests were carried out on a CNC TUR $560 \mathrm{MN}$ lathe. Cutting parameters were selected in accordance with the tool manufacturer's recommendations:

- cutting depth $a p=0.5 \mathrm{~mm}$;

- feedrate $f=0.08 ; 0.13 ; 0.117 ; 0.21 ; 0.24 \mathrm{~mm} / \mathrm{rev}$;

- cutting speed $v c=35 ; 70 ; 110 \mathrm{~m} / \mathrm{min}$.

WEDM machining, carried out in several passes with appropriately selected energy parameters, allows to reduce HAZ when achieving the assumed surface roughness and in the planned number of repetitions. Process parameters are presented in the table. The cut took place in a spray of distilled water. The wire electrode diameter $(0.25 \mathrm{~mm})$ used in the tests meets the requirements for cutting material with a height of $10 \mathrm{~mm}$.

Due to multi-axis control, modern electro-discharge machine tools allow cutting complex shapes, including cones. The design of the Agiecut Sprint EDM cutter, on which machining was carried out in these tests, enables cutting in five controlled axes. Cutting was carried out by spraying without flooding the bathtub. Spray cutting is characterized by higher heating of the machined material.

TABLE. The most important WEDM parameters at the next stages of cutting

\begin{tabular}{|c|c|c|c|c|c|}
\hline $\mathrm{Nr}$ & $\begin{array}{c}\mathrm{U} \\
(\mathrm{V})\end{array}$ & $\begin{array}{c}\mathrm{I} \\
(\mathrm{A})\end{array}$ & $\begin{array}{c}\text { ON } \\
(\mu \mathrm{s})\end{array}$ & $\begin{array}{c}\text { OFF } \\
(\mu \mathrm{s})\end{array}$ & $\begin{array}{c}\mathrm{S} \\
(\mathrm{m} / \mathrm{min})\end{array}$ \\
\hline 1 & 80 & 4 & 2 & 10 & 10 \\
\hline 2 & 120 & 8 & 0,5 & 4 & 8 \\
\hline 3 & 80 & 8 & 0,2 & 2,5 & 8 \\
\hline
\end{tabular}

Designations: $U$ - voltage, $I$ - current, $O N$ - discharge time, $O F F$ - pause time between discharges, $S$ - wire rewinding speed 
Roughness tests (2D and 3D) of the elements surface were carried out using a Mitografoy SV-3200 profilograph. The measurements used a diamond needle with a cone rounding radius of $2 \mu \mathrm{m}$ and an angle of $60^{\circ}$. The tip stroke was $800 \mu \mathrm{m}$. The profilograph was equipped with a 3D measuring table with a resolution of $0.05 \mu \mathrm{m}$. The FORMTRACEPACK measurement software and 3D McCube Ultimate analysis were applied.

\section{Results}

Figs. 1 and 2 present results of $R a$ roughness measurements after turning the titanium alloy Ti6Al4V with a cutting speed of 35 and $110 \mathrm{~m} / \mathrm{min}$. It can be stated that regardless of the cutting speed, the use of smoothing blades allows for a significant improvement in the quality of the machined surface or increase in the efficiency of the turning process. As indicated in the cited literature, the smoothing effect of the wiper blades increases as the feedrate increases. In addition, periodic and directional machining traces disappear, which is the effect of removing the roughness peaks by the wiper blade (fig. 3). It can therefore be assumed that, despite the continuous anisotropic structure, its durability will be greater and its operational properties better.

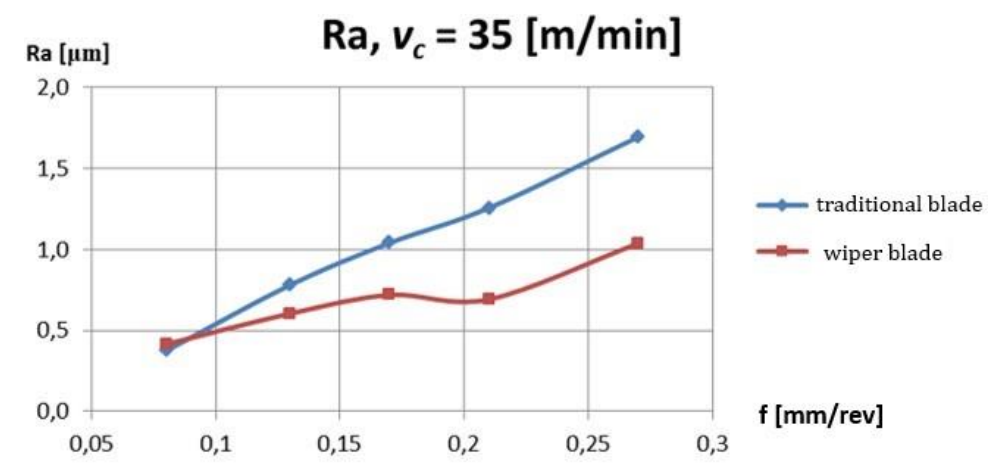

Fig. 1. Surface roughness $R a$ depending on the feed (turning titanium alloy with cutting speed 35 $\mathrm{m} / \mathbf{m i n}$ )

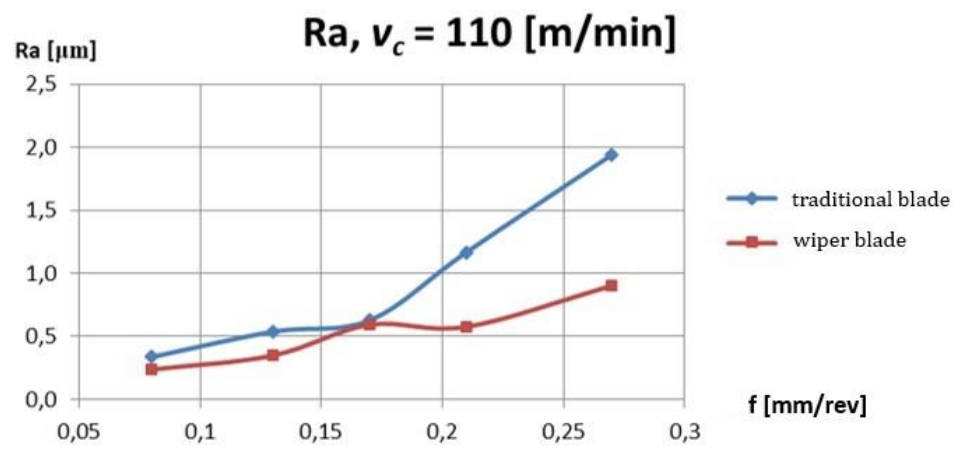

Fig. 2. Surface roughness $\mathrm{Ra}$ depending on the feed (turning of titanium alloy with cutting speed 110 $\mathrm{m} / \mathrm{min}$ )

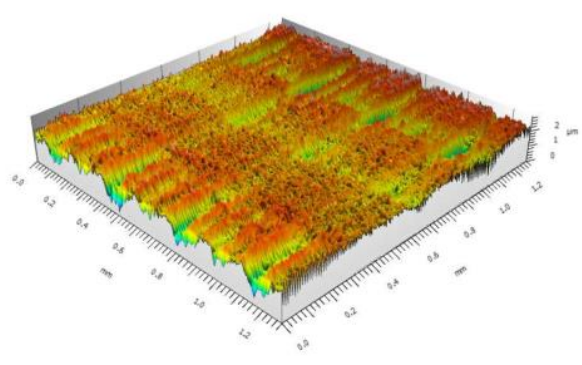

Fig. 3. Geometric structure of the 3D surface after turning with wiper blades

The form of chips produced during turning was also analyzed. Exemplary photos of chips (created during machining with parameters at which it is possible to achieve much lower surface roughness with the help of smoothing blades) are shown in fig. 4. It can be seen that the use of wiper blades does not significantly affect the shape of chips. They have shape and length comparable to chips typical for turning blades with traditional 
geometry. However, it can be seen that increasing the cutting speed makes the chips become more ribbonshaped and longer, which can effectively limit the possibility of turning at this speed. In addition, the cutting speed of $110 \mathrm{~m} / \mathrm{min}$ causes the blades - both conventional and smoothing - to wear more intensively.

Test results of Ti6Al4V alloy after WEDM confirm the relationship between high temperature during the process and changes in properties on the surface of the materials being cut. An analysis is planned after the first, rough cut and after the third - finishing cut. On the surface roughly cut by the electro-discharge method, there are many unevenness, discontinuities and craters of varying depth (fig. 5). These surface imperfections can become stress concentrators under increased load conditions.

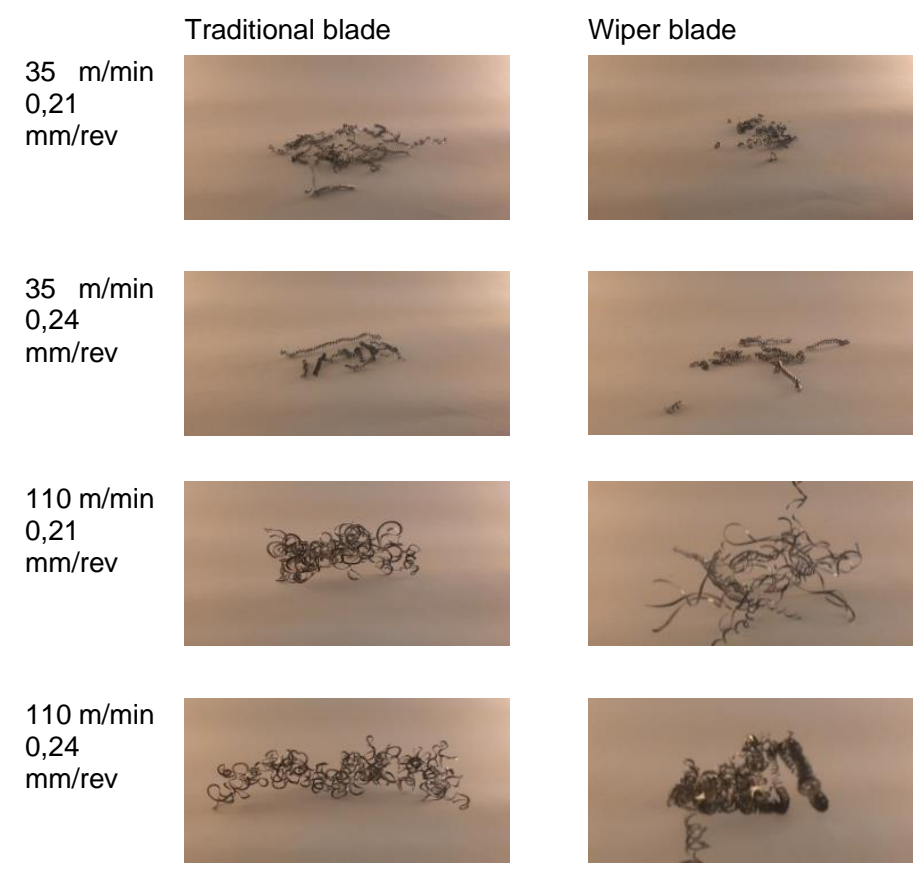

Fig. 4. Chips formed during turning of the Ti6Al4V alloy with traditional and smoothing blades
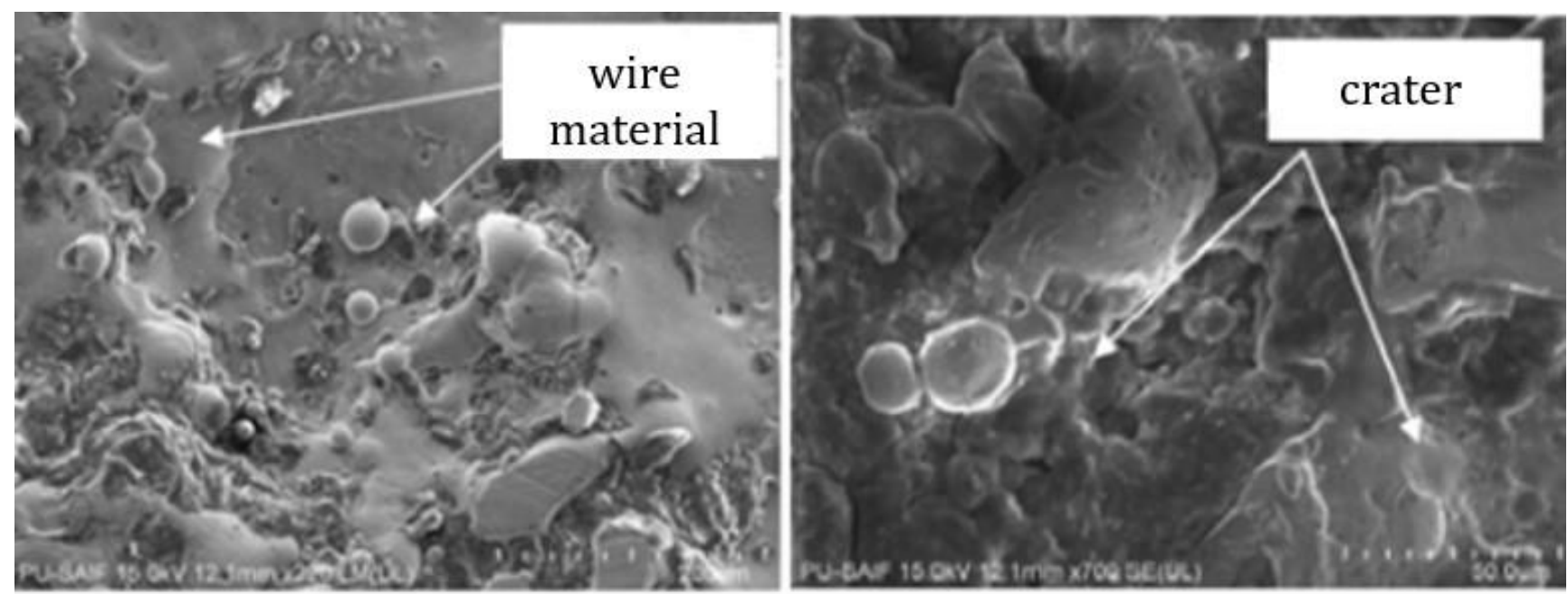

Fig. 5. Microscopic photo of the Ti6Al4V surface after coarse WEDM

Roughness of the surface after rough cutting was unsatisfactory and amounted to $R a=4 \mu \mathrm{m}$. Also, depth of the heat affected zone turned out to be too large - about $50 \mu \mathrm{m}$. However, two finishing cuts resulted in roughness $R a$ less than $1 \mu \mathrm{m}$ and reduced the heat affected zone to $10 \mu \mathrm{m}$ (fig. 6).

The undoubted advantage of electro-discharge machining is isotropicity of the geometric structure of the surface (fig. 7), especially in cases where no special machining marks are required. 


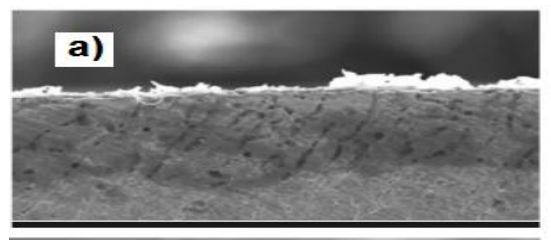

b)

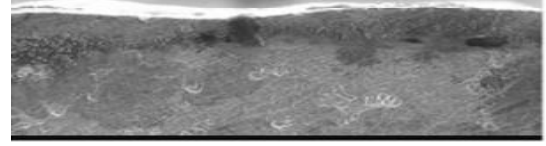

Fig. 6. Image of the HAZ layer depending on the number of passes: a) after roughing, b) after three passes

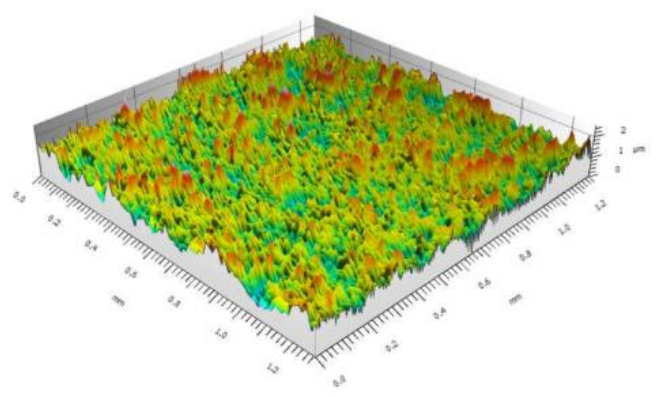

Fig. 7. Isotropic geometric structure of 3D surface after WEDM

\section{Summary}

Presented research results confirm that elements of the Ti6Al4V alloy can be effectively shaped by both machining and EDM. The most important conclusions from the research:

-Wiper plates improve the surface quality. It is possible to increase the feedrate to increase the productivity to get the same roughness as with conventional insert machining.

- The smoothing effect increases with increasing the feedrate and cutting speed. Unfortunately, as the cutting speed increases, the chips become longer and more ribbon-shaped, and blade wear is more intense.

- In the WEDM method, selection of current-time parameters is the most important from the point of view of the possibility of obtaining low surface roughness.

- Limiting the surface roughness $R a$ to a level below $1 \mu \mathrm{m}$ does not require more than three passes during WEDM.

- The right number of passes during WEDM determines the depth of the heat affected zone. Two smoothing cuts reduced the depth of the heat affected zone from $50 \mu \mathrm{m}$ to below $10 \mu \mathrm{m}$.

- Both the use of wiper blades and electro-discharge machining improves geometric structure of the surface it reduces or eliminates its anisotropicity.

To sum up: both methods of machining of selected titanium alloy allow to obtain - in an effective way - the surface of the required quality. The choice of method should result from special recommendations regarding the surface properties of the manufactured item, from a detailed cost analysis and from the means of production available in the particular company.

\section{REFERENCES}

[1] Aspinwall D.K., Soo S.L., Berrisford A.E., Walder G.: "Workpiece surface roughness and integrity after WEDM of Ti-6Al-4V and Inconel 718 using minimum damage generator technology". CIRP Annals - Manufacturing Technology 57 (2008), 187

[2] Cichosz P., „Ekonomiczne aspekty doboru narzędzi skrawających do zadania produkcyjnego”. Mechanik, $10 / 2004$

[3] Karolczak P., Kowalski M., “Analiza wpływu zastosowania ostrzy o geometrii wygładzającej w obróbce kompozytów aluminiowych”. Mechanik. 2013, R. 86, nr 8/9, s. 295-303.

[4] Kruszyński B., Stachurski W., Zgórniak P., „Wpływ warunków obróbki podczas toczenia ostrzami typu wiper na jakość powierzchni obrobionej i siły skrawania”. , Inżynieria Maszyn, tom: R.15, z.4, 2010 
[5] Lin H.C., Lin K.M., Cheng I.S., "The electro discharge machining characteristics of TiNi shape memory alloys". Journal of Material Science, 36 (2001) 399.

[6] Natsu W., Kunieda M., Nishiwaki N., "Study on influence of inter-electrode atmosphere on carbon adhesion and removal amount". Int J Electr Mach 2004, 9,43-50

[7] Pasam V.K. Swapna M., "Optimizing Surface Finish in WEDM Using the Taguchi Parameter Design Method". J. Of the Braz. Soc. of Mech. Sci. \& Eng XXXII (2010) 107.

[8] Stasky P., Janecek J, Harcuba M., Bukovina M., Wagner L., "The effect of microstructure on fatigue performance of Ti-6Al-4V alloy after EDM surface treatment for application in orthopaedics". Journal of the mathematical behaviour of biomedical materials 2011, 4, 1955.

[9] Yadav V., Jain V.K. and Dixit P.M., "Thermal stresses due to electrical discharge machining". International Journal of Machine Tools \& Manufacture 42 (2002), 877 